\title{
PENGARUH KEPEMIMPINAN DAN KOMPENSASI FINANSIAL TERHADAP PRODUKTIVITAS KERJA KARYAWAN RUMAH SAKIT UIN JAKARTA
}

\author{
Edmon Daris*
}

\begin{abstract}
ABSTRAK
Tujuan penelitian ini adalah untuk mengetahui dan menganalisis pengaruh kepemimpinan dan konpensasi finansial terhadap produktivitas kerja karyawan Rumah Sakit UIN Jakarta. Objek penelitian ini terdiri dari dua variabel bebas (indipenden) dan satu variabel terikat (dependen). Adapun variabel indipenden dalam penelitian ini adalah kepemimpinan (X1) dan konpensasi finansial (X2) serta variabel terikat adalah produktivitas kerja (Y). Sedangkan objek penelitiannya adalah karyawan Rumah Sakit UIN Jakarta. Pengumpulan data primer diperoleh dengan melakukan penelitian secara langsung ke lapangan atau peninjauan langsung ke unit pengamatan, yaitu pada Rumah Sakit UIN Jakarta. Penelitian kepustakaan ini dilakukan untuk mendapatkan data sekunder, yaitu dengan mencari dan mempelajari berbagai teori yang ada hubungannya dengan masalah yang sedang diteliti. Selain itu juga peneliti mengumpulkan dan mengolah data dari jurnal, tesis, skripsi, dan artikel serta situs internet. Skala yang digunakan dalam penelitian untuk pembobotan item kuisioner adalah skala Likert. Kesimpulan dari penelitian ini adalah sebagai berikut: (1) Kepemimpinan dan konpensasi finansial berpengaruh positif terhadap produktivitas kerja karyawan Rumah Sakit UIN Syarif HIdayatullah Jakarta, (2) Kepemimpinan lebih berpengaruh terhadap produktivitas kerja karyawan Rumah Sakit UIN Syarif HIdayatullah Jakarta jika dibandingkan dengan motivasi kerja, (3) Perubahan produktivitas kerja karyawan Rumah Sakit UIN Syarif Hidayatullah Jakarta dalam jangka pendek tidak respon terhadap perubahan kepemimpinan dan motivasi kerja. Sedangkan saran dari penelitian ini adalah sebagai berikut: (1) Meningkatkan kepemimpinan akan meningkatkan produktivitas kerja karyawan Rumah Sakit UIN Syarif Hidayatullah Jakarta, (2) Penelitian lanjutan untuk melihat respon produktivitas kerja karyawan Rumah Sakit UIN Syarif Hidayatullah Jakarta dalam jangka panjang akibat perubahan kepemimpinan dan konpensasi finansial.
\end{abstract}

Kata kunci: karyawan, kompensasi finansial, kepemimpinan, produktivitas, rumah sakit

\begin{abstract}
The purpose of this study is to determine and to analyze the effect of leadership and financial compensation on employees productivity of UIN Jakarta Hospital. The object of this study consists of two independent variables and one dependent variable. The independent variables are leadership (X1) and financial compensation (X2) while the dependent variable is labor productivity (Y). The study object is employees of UIN Jakarta Hospital. The
\end{abstract}


collection of primary data is obtained by conducting research directly into field or direct observation in the observation unit, namely UIN Jakarta hospital. The research literature is done to obtain secondary data, i.e. by finding and studying the various theories that have to do with issues that are being investigated. In addition, we collect and process data from journals, theses, articles, and internet sites. The scale used in this study for weighting item questionnaire is Likert scale. The conclusions of this study are as follows: (1) leadership and financial compensation positively effect employees productivity of UIN Jakarta hospital, (2) leadership has more effect on employees productivity of UIN Jakarta hospital while compared with the motivation to work, (3) Changes in the employees productivity of UIN Jakarta in the short term does not response to changes in leadership and motivation. The suggestion of this study are as follows: (1) Improving leadership will improve the productivity of employees of UIN Jakarta Hospital, (2) Further studies to look at the response of the employees productivity of UIN Jakarta hospital in the long term due to changes in leadership and financial compensation.

Keywords: employees, financial compensation, leadership, productivity, hospital

\section{PENDAHULUAN}

\section{Latar Belakang}

Faktor-faktor penting yang mempengaruhi produksi atau output suatu kegiatan di antaranya adalah: Peningkatan pendidikan atau kualitas SDM, pergeseran keunggulan komperatif, perubahan teknologi,penemuan sumber-sumber bahan baku baru (new recources) untuk produksi, dan akumulasi barang modal. Semua ini memungkinkan untuk melakukan inovasi dalam produk atau proses produksi dan pertumbuhan produktivitas sektoral dari faktor-faktor produksi yang digunakan. Arthur Lewis (dalam Jhingan 2000).

Tekanan atau stres pada batas tertentu memang diperlukan karena stres dapat membuat seseorang bisa bekerja memenuhi target. Tapi stres yang berlebihan ternyata bisa menimbulkan penyakit seperti radang lambung sampai gangguan jantung. Stres karena pekerjaan bisa membuat orang menjadi pelupa. Hal itu menunjukkan bahwa ia sudah kelebihan informasi sehingga tidak mampu menyimpannya lagi (Kalbe Farma : 2007).

Dari hasil survei pendahuluan terhadap Rumah Sakit UIN Jakarta yang ada pada 8 Maret 2013, diperoleh informasi sebagai berikut :

Tabel 1.

Item pertanyaan 1

Apakah perusahaan memiliki SDM yang baik dan bagus?

\begin{tabular}{ccc}
\hline Jawaban & Jumlah & Prosentase \\
\hline Ya & 8 & $80,00 \%$ \\
Tidak & 2 & $20,00 \%$ \\
Jumlah & 10 & $100,00 \%$ \\
\hline
\end{tabular}

Sumber : data diolah 
Dari Tabel 1. terlihat bahwa $80 \%$ industri yang berada di Rumah Sakit UIN Jakarta memilki tenaga kerja yang baik, artian perusahaan memiliki kinerja yang baik. Sehingga, jika hal ini berlangsung terus menerus akan dapat menhasilkan produksi yang baik.

\section{Tabel 2.}

Item pertanyaan 2

Apakah setiap SDM memiliki loyalitas

kerja yang dapat diatur dengan efektif?

\begin{tabular}{lcc}
\hline \multicolumn{1}{c}{ Jawaban } & Jumlah & Prosentase \\
\hline Ya & 6 & $60,00 \%$ \\
Tidak & 4 & $40,00 \%$ \\
Jumlah & 10 & $100,00 \%$ \\
\hline
\end{tabular}

Sumber : data diolah

Dari data Tabel 2, terlihat bahwa $60 \%$ manajer berpendapat harus dapat mengatur bawahannya dalam jumlah yang cukup banyak. Sehingga dengan kondisi bawahan yang banyak, manajer dituntut untuk memiliki kemampuan yang baik dalam segala hal, khususnya dalam mengarahkan bawahan-bawahannya. Jika hal tersebut berlangsung terus menerus, kemungkinan para manajer tertekan dengan tuntutan-tuntutan tersebut, sehingga dapat menyebabkan stres kerja.

Tabel3.

Item pertanyaan 3

Apakah perusahaan melibatkan semua pihak terkait dalam mengambil keputusan?

\begin{tabular}{lcc}
\hline \multicolumn{1}{c}{ Jawaban } & Jumlah & Prosentase \\
\hline Pernah & 10 & $100,00 \%$ \\
Tidak pernah & 0 & $0,00 \%$ \\
\hline
\end{tabular}

\begin{tabular}{lll}
\hline Jumlah & 10 & $100,00 \%$ \\
\hline
\end{tabular}

Sumber : data diolah

Dilihat dari Tabel3, 60\% responden beranggapan bahwa perusahaan melibatkan setiap pihak yang berkepentingan dalam pengambilan keputusan. Hal ini menunjukkan sebagian besar Rumah Sakit UIN Jakarta mengarah pada desentralisasi organisasi. Hal ini tentu akan mempermudah para karyawan atau manajer menengah dalam mengambil keputusan, karena tidak perlu menunggu penetapan keputusan yang diambil oleh manajemen puncak. Sehingga hal ini akan sedikit meringankan beban yang harus ditanggung oleh manajemen puncak.

\section{Tabel 4.}

Item pertanyaan 4

Apakah anda termasuk tipe pribadi yang mengukur kesuksesan dilihat dari kuantitas yang dapat dicapai?

\begin{tabular}{lcc}
\hline \multicolumn{1}{r}{ Jawaban } & Jumlah & Prosentase \\
\hline Ya & 8 & $80,00 \%$ \\
Tidak & 2 & $20,00 \%$ \\
Jumlah & 10 & $100,00 \%$ \\
\hline
\end{tabular}

Sumber : data diolah

Kesimpulan dari pernyataan ini, adalah bahwa sebagian besar manajer memandang bahwasannya kesuksesan itu dapat diukur dari kuantitas yang dapat dicapai. Sehingga dapat disimpulkan bahwa para manajer tersebut memiliki tipe kepribadian A. Dimana disebutkan sebelumnya bahwa seseorang yang memiliki tipe kepribadian A memiliki 
peluang yang cukup besar mengalami stres kerja.

Tabel5.

Item pertanyaan 5

Apakah anda pernah mengalami stres kerja?

\begin{tabular}{lcc}
\hline \multicolumn{1}{c}{ Jawaban } & Jumlah & Prosentase \\
\hline Pernah & 10 & $100,00 \%$ \\
Tidak pernah & 0 & $0,00 \%$ \\
Jumlah & 10 & $100,00 \%$ \\
\hline
\end{tabular}

Sumber : data diolah

Jawaban Tabel 5, menunjukkan fenomena bahwa semua manajer yang dijadikan sebagai responden pernah mengalami stres kerja. Dimana kemungkinan besar penyebabnya adalah faktor organisasi dan individu/kepribadian. Hasil penelitian pendahuluan di atas, menunjukkan pengukuhan teori yang dikemukakan oleh Robbins dan Luthans tentang adanya hubungan antara dimensi struktur organisasi dan tipe kepribadian terhadap stres kerja.

Dengan kondisi industri/perusahaan seperti itulah, maka penelitian ini dilakukan untuk mengkaji pengaruh dimensi struktur organisasi, dan tipe kepribadian terhadap tingkat stres kerja manajer SDM dan produktipitas Rumah Sakit UIN Jakarta.

\section{Rumusan Masalah}

Dari latar belakang yang telah dikemukakan di atas maka dapat diidentifikasi masalah sebagai berikut:

1. Apakah terdapat pengaruh kepemimpinan terhadap sumberdaya manusia dalam meningkatkan produktivitas kerja karyawan Rumah Sakit UIN Jakarta?

2. Apakah terdapat pengaruh konpensasi finansial terhadap sumberdaya manusia dalam meningkatkan produktivitas kerja karyawan Rumah Sakit UIN Jakarta?

\section{Tujuan Penelitian}

Adapun maksud dari penelitian ini adalah untuk mengetahui dan memperoleh data-data mengenai pengaruh kepemimpinan dan motivasi kerja pada Rumah Sakit UIN Jakarta . Berdasarkan perumusan masalah di atas, maka tujuan penelitian ini adalah untuk mengetahui dan menganalisis :

1. Pengaruh kepemimpinan terhadap produktivitas kerja karyawan Rumah Sakit UIN Jakarta

2. Pengaruh konpensasi finansial terhadap produktivitas kerja karyawan Rumah Sakit UIN Jakarta

\section{Hipotesis Penelitian}

Berdasarkan identifikasi masalah dan kerangka pemikiran, maka dapat dikemukakan hipotesis penelitian sebagai berikut :

1. Diduga terdapat pengaruh positif kepemimpinan terhadap produktivitas kerja karyawan Rumah Sakit UIN Jakarta.

2. Diduga terdapat pengaruh positif konpensasi finansial terhadap produktivitas kerja karyawan Rumah Sakit UIN Jakarta. 


\section{METODE PENELITIAN}

\section{Objek Penelitian}

Objek penelitian ini terdiri dari dua variabel bebas (indipenden) dan satu variabel terikat (dependen).Adapun variabel indipenden dalam penelitian ini adalah kepemimpinan (X1) dan konpensasi finansial (X2) serta variabel terikat adalah produktivitas kerja (Y). Sedangkan objek penelitiannya adalah karyawan Rumah Sakit UIN Jakarta.

\section{Pengumpulan Data}

Metode pengmpulan data dengan metode survey primer dan sekunder. Pengumpulan data primer diperoleh dengan melakukan penelitian secara langsung ke lapangan atau peninjauan langsung ke unit pengamatan, yaitu pada Rumah Sakit UIN Jakarta. Dimana pengumpulan data diperoleh dengan cara wawancara atau hasil pengisian angket oleh responden yang dijadikan sampel dalam penelitian. Penelitian kepustakaan ini dilakukan untuk mendapatkan data sekunder, yaitu dengan mencari dan mempelajari berbagai teori yang ada hubungannya dengan masalah yang sedang diteliti. Selain itu juga peneliti mengumpulkan dan mengolah data dari jurnal, tesis, skripsi, dan artikel serta situs internet. Sedangkan skala yang digunakan dalam penelitian untuk pembobotan item kuisioner adalah skala Likert. Skala Likert adalah skala yang digunakan untuk mengukur sikap, pendapat, dan persepsi seseorang atau sekelompok orang tentang fenomena sosial (Sugiyono, 2007 : 86).।
Setiap jawaban responden berturutturut diberi nilai 3, 2, 1, apabila item pernyataan berindikasi positif dan sebaliknya, setiap jawaban responden berturut-turut diberi nilai 1, 2, 3, jika item pernyataan berindikasi negatif. Adapun tingkat penskorannya dapat dilihat dari tabel berikut :

Tabel 6.

Skoring jawaban responden

\begin{tabular}{ccc}
\hline Kriteria & $\begin{array}{c}\text { Pernyataan } \\
\text { Positif }(+)\end{array}$ & $\begin{array}{c}\text { Pernyataan } \\
\text { Negatif }(-)\end{array}$ \\
\hline Setuju & 3 & 1 \\
Ragu-ragu & 2 & 2 \\
Tidak setuju & 1 & 3 \\
\hline
\end{tabular}

\section{Metode Analisis Data}

Teknik analisa data yang digunakan adalah analisa regresi linier berganda, dengan menggunakan bantuan komputer dengan program atau software SPSS for windows ver 10.00. Hasil analisis regresi adalah berupa koefisien untuk masingmasing variabel indipenden sehingga membentuk persamaan regresi, dimana persamaan umum regresi berganda adalah sebagai berikut (Mason, 1999 : 102) :

$$
\mathrm{Y}^{\prime}=\alpha+\beta_{1} \mathrm{X}_{1}+\beta_{2} \mathrm{X}_{2}+\ldots+\beta_{\mathrm{k}} \mathrm{X}_{\mathrm{k}}+\mathrm{e}
$$

Dimana :

$$
\begin{aligned}
\mathrm{Y}= & \text { Variabel dependen; } \\
\alpha= & \text { Konstanta (intersep) yang } \\
& \text { menunjukkan nilai Y pada } \\
& \text { saat semua variabel } \\
& \text { independen (Xi) bernilai nol, } \\
& \text { yang merupakan titik potong } \\
& \text { dengan sumbu Y } \\
\beta_{1}= & \text { Koefisien regresi parsial (slope) } \\
& \text { atau cukup koefisien regresi }
\end{aligned}
$$


yang menunjukkan perubahan

bersih nilai variabel dependen

(Y) per unit perubahan $\mathrm{X} 1$

dengan menganggapX2

konstan;

$\beta_{2}=$ Koefisien regresi parsial (slope)

atau cukup koefisien regresi

yang menunjukkan perubahan

bersih nilai variabel dependen

(Y) per unit perubahan X2

dengan menganggapX1

konstan;

$\mathrm{X}_{1}, \mathrm{X}_{2}=$ Variabel independen.

\section{Persamaan Model dan Uji Asumsi Klasik}

Adapun persamaan regresi dalam penelitian ini adalah sebagai berikut :

$\mathrm{Y}=\alpha+\beta_{1} \mathrm{X}_{1}+\beta_{2} \mathrm{X}_{2}+\varepsilon$

Dimana :

$\mathrm{Y}=$ Variabel produktivitas kerja;

$\alpha=$ Konstanta (intersep) yang menunjukkan nilai Y pada saat semua variabel independen (Xi) bernilai nol;

$\mathrm{B}_{1}=$ Koefisien regresi parsial (slope) atau cukup koefisien regresi yang menunjukkan perubahan bersih nilai variabel produktivitas kerja (Y) per unit perubahan variabel kepemimpinan dengan menganggapvariabel motivasi kerja konstan;

$\beta_{2}=$ Koefisien regresi parsial (slope) atau cukup koefisien regresi yang menunjukkan perubahan bersih nilai variabel produktivitas $\operatorname{kerja}(\mathrm{Y})$ per unit perubahan variabel motivasi kerja dengan menganggapvariabel

kepemimpinan konstan; $\mathrm{X}_{1}=$ Variabel kepemimpinan;

$\mathrm{X}_{2}=$ Variabel konpensasi finansial

Secara umum, analisis regresi merupakan studi mengenai ketergantungan variabel terikatdengan satu atau beberapa variabel bebas, dengan tujuan untuk mengestimasi/memprediksi rata-rata nilai variabel dependen berdasarkan nilai variabel indipenden yang diketahui. Teknik estimasi ini biasa disebut Ordinary Least Squares (OLS atau metode kuadrat terkecil), karena intinya adalah meminimumkan jumlah dari kuadrat kesalahan setiap observasi dari garis regresi (Nanang, $2006: 25$ ).

Asumsi utama yang mendasari model regresi linear klasik dengan menggunakan metode OLS adalah (Nanang, $2006: 25)$ :

1) Model regresi linear, artinya linear dalam parameter;

2) Nilai-nilai variabel independent (X) adalah nonstokastik, artinya nilai $\mathrm{X}$ dianggap tetap pada setiap kali percobaan yang dilakukan berulang;

3) Nilai rat-rata eror adalah nol;

4) Homoskedastisitas, artinya varians semua variabel adalah sama/tidak terjadi heteroskedastisitas;

5) Nonmultikolinieritas, artinya tidak ada korelasi yang cukup kuat antar variabel independen dalam model regresi; 
6) Non-otokorelasi, artinya tidak ada korelasi diantara data pengamatan yang berurutan dalam satu variabel;

7) Distribusi eror mendekati sebaran normal.

Analisis regresi linier berganda mensyaratkan beberapa asumsi yang harus dipenuhi agar penaksiran parameter dan koefisien regresi tidak bias. Untuk itu sebelum dilakukan analisis regresi berganda, terlebih dahulu dilakukan pengujian terhadap asumsi-asumsi yang meliputi asumsi multikolinearitas, autokorelasi, heteroskedastisitas dannormalitas (Nanang, 2006 : 24).

\section{Uji Multikolinearitas}

Pengujian ini bertujuan untuk menguji apakah model regresi ditemukan adanya korelasi antar variabel bebas (independen). Model regresi yang baik seharusnya tidak terjadi korelasi di antara variabel bebas. Jika variabel bebas saling berkorelasi, maka variabel-variabel ini tidak ortogonal. Variabel ortogonal adalah variabel bebas yang nilai korelasi antar sesama variabel bebas sama dengan nol. Untuk mendeteksi ada atau tidaknya multikolinearitasadalah sebagai berikut (Imam, $2002: 57$ ) :

1. Nilai R2 yang dihasilkan oleh suatu estimasi model regresi empiris sangat tinggi, tetapi secara individual variabel-variabel bebas banyak yang tidak signifikan mempengaruhi variabel terikat;

2. Menganalisis matrik korelasi variabelvariabel bebas. Jika antar variabel bebas ada korelasi yang cukup tinggi (umumnya diatas 0,90 ), maka hal ini merupakan indikasi adanya multikolinearitas. Tidak adanya korelasi yang tinggi antar variabel bebas tidak berarti bebas dari multikolinearitas. Multikkolinearitas dapat disebabkan adanya efek kombinasi dua atau lebih variabel bebas.

3. Multikolinearitas dapat juga dilihat dari nilai tolerance dan lawannya atau variance inflation factor (VIF).

\section{Uji Autokorelasi}

Uji autokorelasi bertujuan untuk menguji apakah dalam suatu model regresi linier ada korelasi antara kesalahan pengganggu pada periode $t$ dengan kesalahan pada periode $\mathrm{t}-1$ (sebelumnya). Jika terjadi korelasi maka dinamakan ada problem autokorelasi. Autokorelasi muncul karena observasi yang berurutan sepanjang waktu berkaitan satu sama lain (Imam, 2002 :61).

Untuk mendeteksi pelanggaran asumsi korelasi, maka uji statistik yang digunakan adalah uji Durbin Watson dengan hipotesis :

$$
\begin{aligned}
& \mathrm{H}_{0} \text { : Tidak terdapat autokorelasi }(\mathrm{r}=0) \\
& \mathrm{H}_{1} \text { : Terdapat autokorelasi }(\mathrm{r} \quad 0)
\end{aligned}
$$

Pengambilan keputusan ada tidaknya autokorelasi :

1. Bila nilai DW terletak antara batas atas atau upper bound (du) dan $(4-\mathrm{du})$ maka koefisien autokorelasi sama dengan nol, berarti tidak ada autokorelasi; 
2. Bila nilai DW lebih rendah daripada batas bawah atau lower bound (dl), maka koefisien autokorelasi lebih besar daripada nol, berarti ada autokorelasi positif;

3. Bila nilai DW lebih besar daripada (4dl), maka koefisien autokorelasi lebih kecil daripada nol, berarti ada autokorelasi negatif;

4. Bila nilai DW terletak di antara batas atas (du) dan batas bawah (dl) atau DW terletak antara $(4-\mathrm{du})(4-\mathrm{dl})$, maka hasilnya tidak dapat disimpulkan.

\section{Uji Heteroskedastisitas}

Uji heteroskedastisitas bertujuan menguji apakah dalam model regresi terjadi ketidaksamaan variance dari residual satu pengamatan ke pengamatan yang lain. Jika variance dari residual satu pengamatan ke pengamatan yang lain tetap, maka disebut homoskedastisitas dan jika berbeda disebut heteroskedastisitas. Model regresi yang baik adalah yang homoskedastisitas atau tidak terjadi heteroskedastisitas.

\section{Pengujian Hipotesis Penelitian}

Adapun pengujian hipotesis dalam penelitian ini dengan menggunakan dua cara, yaitu pengujian secara bersama-sama (simultan) dan pengujian secara individual (parsial).

\section{Pengujian Hipotesis Secara Keseluruhan (Simultan)}

Hipotesis pada penelitian secara keseluruhan ini adalah sebagai berikut :
$\mathrm{H}_{0}: \beta_{1}=\beta_{2}=0$ artinya semua variabel bebas $\left(\begin{array}{lll}X_{1} & \text { dan } & X_{2}\end{array}\right)$ yang dihipotesiskan secara serentak tidak berpengaruh terhadap variabel tak bebas (Y).

$\mathrm{H}_{1}$ : tidak semua $\beta_{\mathrm{i}}=0$ artinya variabel bebas $\left(\begin{array}{lll}\mathrm{X}_{1} & \text { dan } & \mathrm{X}_{2}\end{array}\right)$ yang dihipotesiskan secara serentak berpengaruh terhadap variabel tak bebas (Y), dimana $i=1,2$.

Jika hipotesis nol benar, ini berimplikasi bahwa semua koefisien regresi sama dengan nol, dan secara logika, tidak berguna kita menduga variabel terikatnya (tingkat produktivitas kerja).Rumus pengujian pada koefisien regresi secara keseluruhan, adalah sebagai berikut :

$$
\mathrm{F}=\frac{\mathrm{R}^{2} /(\mathrm{k}-1)}{1-\mathrm{R}^{2} /(\mathrm{N}-\mathrm{k})}
$$

Dimana :

$\mathrm{R}^{2}=$ koefisien determinasi;

$\mathrm{N}=$ banyaknya populasi;

$\mathrm{K}=$ banyaknya variabel.

Statistik uji diatas mengikuti distribusi $\mathrm{F}$ dengan derajat bebas $\mathrm{V}_{1}=\mathrm{k}-$ 1 dan

$\mathrm{V}_{2}=\mathrm{N}-\mathrm{k}$, adapun kriteria uji hipotesisnya adalah sebagai berikut :

1. JikaFhitung $>F_{\text {tabel }}$ dengan tabel $\alpha=5 \%$, maka H0 ditolak dan H1 diterima, artinya semua variabel independen secara bersama-sama berpengaruh terhadap variabel dependen.

2. Jika $F_{\text {hitung }} \leq \mathrm{F}_{\text {tabel }}$ dengan $\alpha=5 \%$, maka $\mathrm{H}_{0}$ diterima dan $\mathrm{H}_{1}$ ditolak, artinya 
semua variabel independen secara bersama-sama tidak berpengaruh terhadap variabel dependen.

\section{PengujianHipotesis Secara Individu (Parsial)}

Hipotesis individual dilakukan dengan tujuan untuk mengetahui apakah secara individu variabel tersebut secara statistik berpengaruh secara signifikan terhadap variabel dependen. Hipotesis operasional dari pengujian parsial adalah sebagai berikut :

$\mathrm{H}_{0}: \beta_{\mathrm{i}}=0$ artinya variabel bebas ke-i yang dihipotesiskan tidak berpengaruh secara individu terhadap variabel tidak bebasnya.

$\mathrm{H}_{1}: \beta_{\mathrm{i}} \neq 0$ artinya variabel bebas ke-i yang dihipotesiskan berpengaruh secara individu terhadap variabel tidak bebasnya, dimana $\mathrm{i}=1,2$ (uji 2 pihak).

Untuk menguji koefisien regresi secara parsial, rumus pengujiannya adalah sebagai berikut :

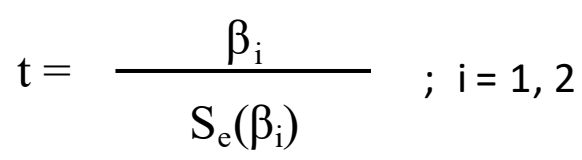

Dimana:

$\mathrm{Bi}_{\mathrm{i}} \quad=$ koefisien regresi ke- $\mathrm{i}$

$\mathrm{S}_{\mathrm{e}} \beta_{\mathrm{i}}=$ standar error koefisien regresi ke-i

Statistik uji diatas mengikuti distribusi $\mathrm{t}$ dengan derajat bebas N-k-1.
Adapun kriteria uji hipotesisnya adalah sebagai berikut :

1. Jika thitung $>$ tabel dengan $\alpha=5 \%$, maka $\mathrm{H}_{0}$ ditolak dan $\mathrm{H}_{1}$ diterima, artinya variabel $\mathrm{X}_{\mathrm{i}}$ berpengaruh terhadap variabel $\mathrm{Y}$;

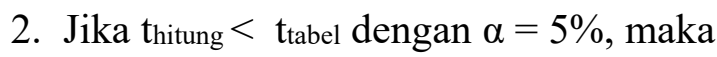
$\mathrm{H}_{0}$ diterima dan $\mathrm{H}_{1}$ ditolak, artinya variabel $X_{\mathrm{i}}$ tidak berpengaruh terhadap variabel $\mathrm{Y}$.

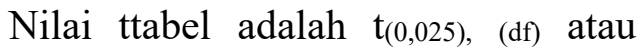
$t_{(0,025),(n-k-1)}$ atau $t_{(0,025),(17) .}$

\section{HASIL DAN PEMBAHASAN}

Penelitian ini akan mempelajari pengaruh kepemimpinan dan konpensasi financial terhadap produktivitas kerja karyawan Rumah Sakit UIN Jakarta. Model yang digunakan adalah model sebab akibat atau kausalitas dari kepemimpinan dan motivasi kerja terhadap produktivitas kerja.Untuk melihat peranan variabel bebas dalam menjelaskan variabel tak bebas digunakan uji koefisien determinasi (R2), sedangkan untuk melihat pengaruh variabel bebas secara bersama-sama terhadap variabel tak bebas digunakan uji statistik F.Untuk menguji apakah masing-masing variabel bebas berpengaruh nyata secara statistik terhadap variabel tak bebas digunakan uji statistik t.Untuk melihat respon perubahan variabel tak bebas terhadap perubahan variabel bebas digunakan nilai-nilai elastisitas.

Hasil pendugaan persamaan regresi linear berganda dari Pengaruh Kepemimpinan dan Konpensasi Finansial 
Terhadap Produktivitas Kerja Karyawan Rumah Sakit UIN Syarif Hidayatullah Jakarta adalah sebagai berikut :

$$
\begin{array}{r}
\mathrm{Y}=0,131+0,244 \mathrm{X} 1+0,232 \mathrm{X} 2 \\
(0,926)(2,379) \quad(0,797) \\
\mathrm{R}^{2}=0,736 \quad \mathrm{~F}=6,573 \quad \mathrm{DW}=1,140
\end{array}
$$

Dimana:

$$
\begin{aligned}
& \mathrm{Y}=\text { produktivitas kerja } \\
& \mathrm{X}_{1}=\text { kepemimpinan } \\
& \mathrm{X}_{2}=\text { kompensasi finansial }
\end{aligned}
$$

Hasil pendugaan persamaan regresi linear berganda menunjukkan bahwa nilai statistic DW adalah sebesar 1,140 yang berarti persamaan produktivitas kerja tersebut tidak mengalami autokorelasi, dimana auto korelasi hanya mengurangi efisiensi pendugaan dan tidak menimbulkan bias koefisien regresi (Pindyck and Rubinfeld, 1991).Koefisien determinasi R2 adalah sebesar 0,736 yang berarti sebanyak 73,6 persen variasi perubahan produktivitas kerja karyawan Rumah Sakit UIN Jakarta dapat dijelaskan oleh variasi perubahan kepemimpinan dan konpensasi finansial. Dengan demikian 16,4 persen variasi perubahan produktivitas kerja karyawan Rumah Sakit UIN Jakarta dijelaskan oleh variabel lain yang belum dimasukkan dalam model.

Nilai statistik F adalah sebesar 6,873 yang menunjukkan bahwa secara bersamasama variabel kepemimpinan dan konpensasi financial berpengaruh nyata terhadap variabel produktivitas kerja karyawan Rumah Sakit UIN Jakarta. Uji statistik $\mathrm{t}$ berguna untuk melihat pengaruh masing-masing variabel bebas terhadap variabel tak bebas. Uji statistik $\mathrm{t}$ untuk variabel kepemimpinan adalah sebesar 2,379 dengan derajat bebas $n-1$, maka nyata pada taraf kepercayaan 95 persen, sedangkan uji statistik $\mathrm{t}$ untuk konpensasifinansialadalah sebesar 0,797 dengan derajat bebas $n-1$, maka nyata pada taraf kepercayaan 50 persen.

Untuk melihat respon variabel tak bebas terhadap perubahan masing-masing variabel bebas dari persamaan regressi linear berganda digunakan nilai-nilai elastisitas.Hasil perhitungan elastisitas jangka pendek berguna untuk menjelaskan respon perubahan variabel tak bebas akibat dari perubahan variabel bebas. Semakin besar nilai elastisitas akan semakin respon perubahan variabel tak bebas akibat perubahan variabel bebas dan sebaliknya semakin kecil nilai elastisitas akan menyebabkan kurang respon perubahan variabel tak bebas akibat perubahan variabel bebas.Hasil penelitian menunjukkan bahwa nilai elastisitas jangka pendekvariabel kepemimpinan adalah sebesar 0,253 yang berarti perubahan produktivitas kerja karyawan Rumah Sakit UIN Jakarta tidak respon terhadap perubahan kepemimpinan. Nilaielastisitas jangka pendek konpensasifinansialadalah sebesar 0,309 yang berarti perubahan produktivitas kerja karyawan Rumah Sakit UIN Jakarta tidak respon terhadap perubahan konpensasifinansial.

\section{Pembahasan}

Produktivitas kerja karyawan Rumah Sakit UIN Syarif Hidayatullah Jakarta dipengaruhi oleh kepemimpinan 
dan konpensasi finansial. Dari hasil penelitian produktivitas kerja karyawan Rumah Sakit UIN Syarif Hidayatullah Jakarta berhubungan positif dengan kepemimpinan dan konpensasi finansial yang berarti dengan peningkatan kepemimpinan dan konpensasi finansial akan meningkatkan produktivitas kerja karyawan Rumah Sakit UIN Syarif Hidayatullah Jakarta. Koefisien regressi dari variabel kepemimpinan adalah sebesar 0,244 yang berarti bahwa peningkatan kepemimpinan sebesar satu satuan akan meningkatkan produktivitas kerja karyawan Rumah Sakit UIN Syarif Hidayatullah Jakarta sebesar 0,244 satuan.Variabel kepemimpinan ini nyata pada taraf kepercayaan 95 persen dalam mempengaruhi produktivitas kerja karyawan Rumah Sakit UIN Syarif Hidayatullah Jakarta. Demikian juga variabel kepemimpinan ini kurang merespon produktivitas kerja karyawan Rumah Sakit UIN Syarif Hidayatullah Jakarta yang ditunjukkan oleh nilai elastisitas yang bersifat inelastis. Koefisien regressi dari variabel motivasi kerja adalah sebesar 0,234 yang berarti bahwa peningkatan kompensasi finansial sebesar satu satuan akan meningkatkan produktivitas kerja karyawan Rumah Sakit UIN Syarif Hidayatullah Jakarta sebesar 0,234 satuan.Variabel konpensasifinansialini hanya nyata pada taraf kepercayaan 50 persen dalam mempengaruhi produktivitas kerja karyawan Rumah Sakit UIN Syarif Hidayatullah Jakarta. Demikian juga dengan melihat nilai elastisitas dapat dinyatakan bahwa variabel konpensasi finansialini kurang merespon produktivitas kerja karyawan Rumah Sakit UIN Syarif Hidayatullah Jakarta yang ditunjukkan oleh nilai elastisitas yang bersifat inelastis.

\section{KESIMPULAN DAN SARAN}

\section{Kesimpulan}

Kesimpulan dari penelitian ini adalah sebagai berikut :

1. Kepemimpinan dan konpensasi finansial berpengaruh positif terhadap produktivitas kerja karyawan Rumah Sakit UIN Syarif HIdayatullah Jakarta.

2. Kepemimpinan lebih berpengaruh terhadap produktivitas kerja karyawan Rumah Sakit UIN Syarif HIdayatullah Jakarta jika dibandingkan dengan motivasi kerja.

3. Perubahan produktivitas kerja karyawan Rumah Sakit UIN Syarif Hidayatullah Jakarta dalam jangka pendek tidak respon terhadap perubahan kepemimpinan dan motivasi kerja.

\section{Saran}

Saran dari penelitian ini adalah sebagai berikut :

1. Meningkatkan kepemimpinan akan meningkatkan produktivitas kerja karyawan Rumah Sakit UIN Syarif Hidayatullah Jakarta.

2. Penelitian lanjutan untuk melihat respon produktivitas kerja karyawan Rumah Sakit UIN Syarif Hidayatullah Jakarta dalam jangka panjang akibat 
perubahan kepemimpinan dan Luthans, Fred. 2005. Organizational

konpensasi finansial.

\section{DAFTAR PUSTAKA}

Admin. 2006. 75\% Garmen Soreang TerhentiAkibat Makin Maraknya Perdagangan Produk Impor. $<$ http://indonesiagarment.com/ne ws $>(14 / 03 / 2006)$.

BPID Kab. Bandung . 2006. Industri \& Perdagangan Penanaman Modal Asing dan

Penanaman Modal dalam Negeri di Kabupaten Bandung. Bandung

$<$ http://disperindag-jabar.go.id $>$ (15/12/ 2006).

Jhingan, M.L. 2000.Development Planning. Singapore: The Mc.Graw-Hill Companies.
Behavior. New York : McGrawHill.

Mason, Robert D. dan Lind, Douglas A. 1999. Teknik Statistika untuk Bisnis dan Ekonomi Edisi 9 Jilid I. Jakarta : Erlangga. . 1999. Teknik Statistika untuk Bisnis dan Ekonomi Edisi 9 Jilid II. Jakarta : Erlangga.

Robbins, Stephen P. 1994. Teori Organisasi Struktur, Desain dan Aplikasi Edisi 3. Jakarta : Penerbit Arcan.

.2006. Perilaku Organisasi. Jakarta : PT. Indeks Gramedia.

Sugiyono. 2007. Metode Penelitian Bisnis. Bandung : CV. Alfabeta.

. 2003. Manajemen Edisi2. Yogyakarta : BPFE Yogyakarta.

* Dosen Program Studi Agribisnis, FST UIN Syarif Hidayatullah Jakarta (Email: edmon.daris@uinjkt.ac.id) 